\title{
Short and longer-term psychological consequences of Operation Cast Lead: documentation from a mental health program in the Gaza Strip
}

Augusto E Llosa ${ }^{1 *}$, Germán Casas ${ }^{2,3}$, Hélène Thomas ${ }^{4}$, Angels Mairal ${ }^{4}$, Rebecca F Grais ${ }^{1}$ and Marie-Rose Moro ${ }^{3,5}$

\begin{abstract}
Background: There is growing recognition of the psychological impact of adversity associated with armed conflict on exposed civilian populations. Yet there is a paucity of evidence on the value of mental health programs in these contexts, and of the chronology of psychological sequelae, especially in prolonged conflicts with repeated cycles of extreme violence. Here, we describe changes in the psychological profile of new patients in a mental health program after the military offensive Cast Lead, in the context of the prolonged armed conflict involving the Gaza Strip.

Methods: This study analyses routinely collected program data from a Médecins Sans Frontières mental health program in the Gaza Strip spanning 2007-2011. Data consist of socio-demographic as well as clinical baseline and follow-up data on new patients entering the program. Comparisons were made through Chi square and Fisher's exact tests, univariate and multivariate logistic and linear regression.
\end{abstract}

Results: PTSD, depression and other anxiety disorders were the most frequent psychopathologies, with 21\% having multiple diagnoses. With a median of nine sessions, clinical improvement was recorded for $83 \%(1122 / 1357)$, and more common for those with separation anxiety, acute and posttraumatic disorders as principal diagnosis (855/1005), compared to depression (141/183, p<0.01). Noted changes proximal to Operation Cast Lead were: a doubling in patient case load with a broader socio-economic background, shorter interval from an identified traumatic event to seeking care, and a rise in diagnoses of acute and posttraumatic stress disorders. Sustained changes included: high case load, more distal triggering events, and increase in diagnoses of other anxiety disorders (especially for children 15 years and younger) and depression (especially for patients 16 years and older).

Conclusion: Evolving changes in patient volume, diagnoses and recall period to triggering events suggest a lengthy and durable effect of an intensified exposure to violence in a context of prolonged conflict. Our findings suggest that mental health related humanitarian relief in protracted conflicts might need to prepare for an increase in patients with changing profiles over an extended period following an acute flare-up in violence.

Keywords: Mental health, Psychological, PTSD, Internally displaced persons, Refugees, Conflict, War, Cast lead, Palestinian, Gaza

\footnotetext{
* Correspondence: Augusto.Llosa@epicentre.msf.org

'Epicentre, 8 rue Saint Sabin, Paris 75011, France

Full list of author information is available at the end of the article
} 


\section{Background}

Prolonged exposure to violence increases the risk of accumulation of major traumatic events and daily life stressors, including physical and economic insecurity, all of which have negative mental and psychosocial consequences [1-4]. A high number of accumulated traumatic life events, economic pressure, and elevated prevalence of depression, anxiety and posttraumatic stress disorder (PTSD) have been found among adults and children in the Gaza Strip [5-9].

Close to a million and a half people live in the 360 square kilometers that make up the Gaza Strip [10]. Crowded, confined and impoverished, the strip's population has faced increasing tension, war and deteriorating living conditions in the last decade. Economic pressure, political changes, and restrictions and violence related to the Al Aqsa intifada, and Israeli military involvement have contributed to noted de-development, increased dislocation and exposure to violence $[9,11,12]$. Shelling during the military offensive Operation Cast Lead (OCL) from 27 December 2008 to 18 January 2009, resulted in between 1,166-1,417 deaths, including 300 children, many more injured, and the destruction of homes and infrastructure, massive displacement and financial loss in the Gaza Strip. This intense, prolonged bombardment and military occupation exposed the community to the conflict to an unprecedented degree, adding economic and psychological stressors while disrupting existing social support networks [13-15].

The Mental Health Services Organization Plan was adopted by the Palestinian Ministry of Health $(\mathrm{MoH})$ in 2004. Besides an MoH run psychiatric hospital, the Gaza Community Mental Health Program and NGOs provide psychological and psychosocial support to this population. After OCL, however, mental health services were temporarily disrupted. The international medical humanitarian organization Médecins Sans Frontières/Doctors without Borders (MSF) has provided free medical support to the population of Occupied Palestinian Territory since 1989. The mental health program in Gaza opened in 2000 and included medical care, social worker assessment and support, psychological evaluation and psychotherapy. Consenting civilian victims of the conflict residing in Gaza, at least one year of age and in need of treatment were eligible for free care. Patients with chronic psychiatric illnesses (schizophrenia, mental retardation, personality disorders) were referred to the Ministry of Health psychiatric hospital for specialized treatment. Therapeutic consultations took into account the social and cultural context, utilized local therapists or translators, $[16,17]$ lasted typically 8-12 sessions, and were guided by principles of interpersonal psychotherapy [18-20]. While additional rigorous assessments are still needed, there appears to be an overall benefit of appropriately targeted psychotherapy in war and other humanitarian crises [4,9,21-23].

Two prior analyses of the mental health project data provide details on the therapeutic approach and patient descriptions from the project's opening in 2000 through 2006 [24] and 2005 through 2008 [21]. The present operational review aims to update this description through 2011 and explore potential changes in diagnoses, severity and treatment outcomes potentially associated with the intensification of the conflict during Cast Lead. This exploratory analysis was intended as descriptive and hypothesis generating.

\section{Methods}

This analysis draws from routinely collected information from the patient database of the MSF mental health program in Gaza Strip for files opened between 2007 and the program's closure in 2011. Analysis includes patient baseline as well as follow-up data.

Semi-structured interviews with standardized questionnaires were used by mental health officers to collect information on socio-demographics, main complaints, presenting symptoms and traumatic event history. Diagnoses and severity at baseline and final session were assigned by MSF psychologists or psychiatrists according to DSM-IV-TR criteria and in accordance to guidelines laid out by the supervising psychiatrist [25]. For simplification and to improve cultural specificity of diagnoses, focus group discussions were conducted at the opening of the program. As a result, the PTSD category included complex-PTSD; [26] dysthymia was included in the depression category; and other anxiety disorders included generalized anxiety disorder, panic disorder, agoraphobia, social and specific phobia.

Disorder severity categories (mild, moderate, severe) considered symptom severity as well as psychological and social impairment. Following initial standardized assessment by mental health officers, where indicated, patients were referred to psychologist, psychiatrist or other medical doctor according to their need. Therapy was either individual, group or dyad (caregiver/child). After 8-12 sessions, the patients' condition was reassessed and therapy was either extended, finished or the patient was referred. Final outcome was qualitatively categorized (resolved, improved, unchanged, worsened) taking into account the patient's perception of their state and the treating psychologist's evaluation of changes in psychological and social functioning, symptom severity, resilience and coping strategies. Reasons for discontinuation of treatment were recorded. Delay to seeking care was computed, where relevant, as the number of weeks between an identified traumatic event and time when care was sought. Its association with the timing of OCL was explored as potential indicator of impact of this 
particularly violent period in the context of a sustained conflict.

Age was categorized as 15 years and younger (child or young adolescent) and above 15 years (older adolescent or adult), corresponding to the differences in the therapeutic intervention process for patients in MSF programs relating to these age categories. Specific OCL exposures were not recorded in the database, but the timing of the patients' initial assessment was later categorized in reference to the war period (number of months before 27 December 2008 or after 17 January 2009). Returning patients (estimated as less than 5\% from operational summaries) were not excluded. Categorical variables were compared by Chi square $\left(\chi^{2}\right)$ and Fisher's exact tests. Odds ratios (OR) and 95\% confidence intervals $(95 \% \mathrm{CI})$ were computed through logistic regressions for dichotomous outcomes. Coefficients ( $($ ) and p-values for ordinal outcomes were computed through linear regression models. Regression coefficients and $\mathrm{OR}$ are from univariate models unless otherwise specified. A p-value lower than 0.05 was considered statistically significant. As the analysis was exploratory and all available data were included, no a priori sample size calculation was performed.
Anonymized patient data were entered into Epidata (Odense, Denmark) and analyzed with STATA 10.1 (College Station, Texas, USA). The program was authorized by local authorities and patients were informed about the use of data in research. Privacy and confidentiality of patients were ensured during the treatment and after the conduct of the analysis. This analysis met the criteria for review of program monitoring data and for exemption from the MSF Ethics Review Board.

\section{Results}

This analysis included 1357 evaluable of 1377 (98.5\%) MSF mental health clinic patients whose treatment started between January 2007 through July 2011. On average during this period, 25 patients each month started treatment; highest monthly averages were noted in the two years following OCL. Patients' age ranged from three to 70 years, with a median of 13 and interquartile range $(\mathrm{IQR})=9-24$ years; $63 \%(\mathrm{n}=738)$ were 15 years of age or younger and 55\% were female. From 2007 through 2011 the proportion of patients 15 years and younger increased, $\mathrm{OR}=0.73(95 \% \mathrm{CI}=0.66-0.80)$, as did, among those at least 16 years of age, the proportion of women, OR = 1.37 (1.25-1.50) (Table 1A).

Table 1 Patient socio-demographic and referral characteristics by year of entry into the MSF program

\begin{tabular}{|c|c|c|c|c|c|c|c|c|c|c|c|c|}
\hline Year & 2007 & & 2008 & & 2009 & & 2010 & & 2011 & & Total & \\
\hline \multicolumn{13}{|l|}{ Demographic } \\
\hline New registrations, $n$ & 149 & & 206 & & 411 & & 388 & & 203 & & 1357 & \\
\hline Monthly Average, n (SD) & 12.4 & $(8.1)$ & 17.2 & $(7.2)$ & 34.3 & (22.8) & 32.3 & $(11.3)$ & 28.9 & $(12.7)$ & 24.7 & (16.0) \\
\hline Adult:child ratio & 1.6 & & 0.8 & & 0.5 & & 0.5 & & 0.4 & & 0.6 & \\
\hline$<15$ y male:female ratio & 1.7 & & 1.0 & & 1.3 & & 1.4 & & 0.9 & & 1.2 & \\
\hline$>15$ y male:female ratio & 1.7 & & 1.8 & & 0.9 & & 1.0 & & 0.8 & & 1.2 & \\
\hline \multicolumn{13}{|l|}{ Socio-economic needs } \\
\hline High need, n (\%) & 78 & $(53.0)$ & 119 & $(61.0)$ & 231 & $(57.0)$ & 251 & $(65.0)$ & 143 & $(70.0)$ & 822 & $(62.0)$ \\
\hline Some need, n (\%) & 61 & $(42.0)$ & 59 & $(30.0)$ & 145 & $(36.0)$ & 119 & (31.0) & 57 & $(28.0)$ & 441 & (33.0) \\
\hline Needs covered, n (\%) & 7 & (5.0) & 17 & $(9.0)$ & 31 & (8.0) & 14 & $(4.0)$ & 3 & $(1.0)$ & 72 & $(5.0)$ \\
\hline Total, n (\%) & 146 & (100) & 195 & $(100)$ & 407 & $(100)$ & 384 & $(100)$ & 203 & $(100)$ & 1335 & $(100)$ \\
\hline \multicolumn{13}{|l|}{ Referral source } \\
\hline MSF outreach, n (\%) & 77 & (52.0) & 110 & $(54.0)$ & 134 & (33.0) & 88 & $(23.0)$ & 45 & (22.0) & 454 & (34.0) \\
\hline Local institution, n (\%) & 17 & $(11.0)$ & 34 & $(17.0)$ & 45 & $(11.0)$ & 31 & (8.0) & 17 & $(8.0)$ & 144 & (11.0) \\
\hline Self, n (\%) & 10 & $(7.0)$ & 20 & $(10.0)$ & 20 & (5.0) & 40 & $(10.0)$ & 28 & $(14.0)$ & 118 & (9.0) \\
\hline Ministry of Health, n (\%) & 12 & (8.0) & 0 & (0) & 1 & $(0.0)$ & 2 & $(1.0)$ & 0 & (0) & 15 & $(1.0)$ \\
\hline Community/family, n (\%) & 25 & $(17.0)$ & 41 & (20.0) & 209 & $(51.0)$ & 223 & (57.0) & 108 & (53.0) & 606 & (45.0) \\
\hline Other, n (\%) & 8 & (5.0) & 0 & (0) & 1 & (0) & 4 & $(1.0)$ & 5 & $(2.0)$ & 18 & (1.0) \\
\hline Total, n (\%) & 149 & (100) & 205 & (100) & 410 & (100) & 388 & (100) & 203 & (100) & 1355 & (100) \\
\hline
\end{tabular}

Monthly average for 2011 and total consider only active portions (January-July) of 2011.

Age not recorded for 5 patients.

Sex not recorded for 2 patients.

Socio-economic needs assessment results not recorded for 22 patients.

Referral source not recorded for 2 patients. 
The majority (93\%) of patients were rated as having high $(n=822)$ or medium $(n=441)$ socio-economic needs during the intake interview. Overall, the proportion of those with high socio-economic needs increased over time, OR 1.18 (1.08-1.30), except briefly after the war in 2009 when there was a greater proportion of new patients with medium to low socioeconomic needs compared to both 2008, OR = 1.19 (0.84-1.69), and 2010, $\mathrm{OR}=1.44$ (1.08-1.92) (Table 1B).

The majority of patients were referred by community/ family (45\%), MSF social workers (34\%) or other institutions (11\%). Community/family and self referrals increased over time compared to those from MSF social workers and other institutions, OR $=1.74$ (1.57-1.92). This trend was most pronounced in 2009 following the war but continued in 2010 and 2011. (Table 1C).

Of 1357 patients seen in this period, 1305 (96\%) expressed that they were exposed to conflict related violence. Overall, 1137 (84\%) considered Israeli Defense Forces (IDF) the source of exposure with this proportion significantly increasing from $72-74 \%$ in 2007 and 2008 respectively to $92 \%$ in $2009\left(\chi^{2}=49.4, \mathrm{p}<0.001\right)$.

Information on traumatic life events was available for 1352 patients, of which 1263 (93\%) reported at least one. On average patients 15 years and younger, reported one event per three life-years ( 0.33 per year) and those older than 15 reported one per decade lived $(0.11$ per year) $(\Omega=$ $0.22, \mathrm{p}<0.001$ ) (Table 2). Adjusted for age, new patients were more likely to report a greater number of traumatic events after OCL $(ß=1.0, \mathrm{p}<0.001)$.

For those with a stated triggering event $(n=1295)$ the median delay to care was 7-12 months, and significantly longer for those 15 years and younger $(B=0.33$, $\mathrm{p}<0.001)$. Following OCL, in 2009 the median delay declined from 7-12 months to $3-6$ months $(B=-0.41$, $\mathrm{p}<0.001$ ) and only $1 \%$ of patients did not identify an event associated with seeking psychological support. Delay significantly rose again in $2010(\beta=1.1, \mathrm{p}<0.001)$ with the majority of patients in 2010 (74\%) and 2011 (59\%) attributing a triggering event more than a year earlier, to the OCL time or before it (Figure 1).

Most common baseline symptoms noted in the younger age group were distress or anxiety followed by inhibition or withdrawal. For adults these were sadness or crying followed by distress or anxiety. One or two patients' main complaints were reported at first visit. Most frequent for children were fear, sleep disturbance, bed-wetting and aggressiveness; for patients older than 15 years these were sleep disturbance, sadness, intrusive memories and anxiety (Table 3 ). After OCL, statistically significant increases (Fishers exact test) were noted in bed-wetting $(\mathrm{p}<0.05)$, sleep disturbance $(\mathrm{p}<0.05)$, and hyperactivity $(\mathrm{p}=0.001)$ among the younger patients, and in grief $(\mathrm{p}<0.01)$ and avoidance $(\mathrm{p}<0.05)$ for the older age group.

Anxiety disorders accounted for 83\% (705/846) of diagnoses of patients 15 years and younger; depression and developmental disorders accounted for 6\%. Compared to 2007-2008, the proportion of those diagnosed with PTSD rose in 2009, $\mathrm{OR}=1.53(1.03-2.27)$; and of other anxiety disorders in 2010, $\mathrm{OR}=1.85(1.17-2.90)$. Compared to 2008, intra-year trends in 2009 were a rise in diagnoses of acute stress disorder (ASD) first quarter, $\mathrm{OR}=5.38$ (1.04-28.6); PTSD second quarter, OR=13.48 (4.6-39.3). Compared to the first six months of 2009, diagnoses of other anxiety disorders and depression increased in the second half of the year, OR=4.97 (2.29-10.80), in addition to communication disorders, attention deficit disorder and separation anxiety, albeit at lower frequencies. In 2010 and 2011 the proportion of new pediatric patients with PTSD and other

Table 2 Traumatic life events by age category for MSF patients, 2007-2011

\begin{tabular}{|c|c|c|c|c|c|c|}
\hline \multirow[t]{2}{*}{ Traumatic life events by age category } & \multicolumn{2}{|c|}{$<15$ years } & \multicolumn{2}{|c|}{$\geq 15$ years } & \multicolumn{2}{|l|}{ Total } \\
\hline & $\mathbf{N}$ & $(\%)$ & $\mathbf{N}$ & $(\%)$ & $\mathbf{N}$ & (\%) \\
\hline Sexual violence & 6 & (1) & 9 & $(2)$ & 15 & (1) \\
\hline Physical injury & 123 & $(15)$ & 250 & $(49)$ & 373 & (28) \\
\hline Close family member killed & 250 & (30) & 186 & $(37)$ & 436 & (32) \\
\hline Close family member died from illness & 51 & (6) & 60 & $(12)$ & 111 & (8) \\
\hline Witness to murder or physical abuse & 451 & (54) & 347 & $(69)$ & 798 & (59) \\
\hline Received threats & 379 & (45) & 271 & $(54)$ & 650 & (48) \\
\hline Incarceration & 35 & (4) & 52 & $(10)$ & 82 & (6) \\
\hline Loss of property & 458 & (55) & 201 & $(40)$ & 659 & (49) \\
\hline Forced to flee & 472 & (56) & 190 & (38) & 662 & (49) \\
\hline Break-up of nuclear family & 77 & (9) & 46 & (9) & 123 & (9) \\
\hline Total patients & 836 & (100) & 506 & $(100)$ & 1352 & $(100)$ \\
\hline
\end{tabular}

Age not recorded for 5 patients.

Traumatic events not recorded for 5 patients. 


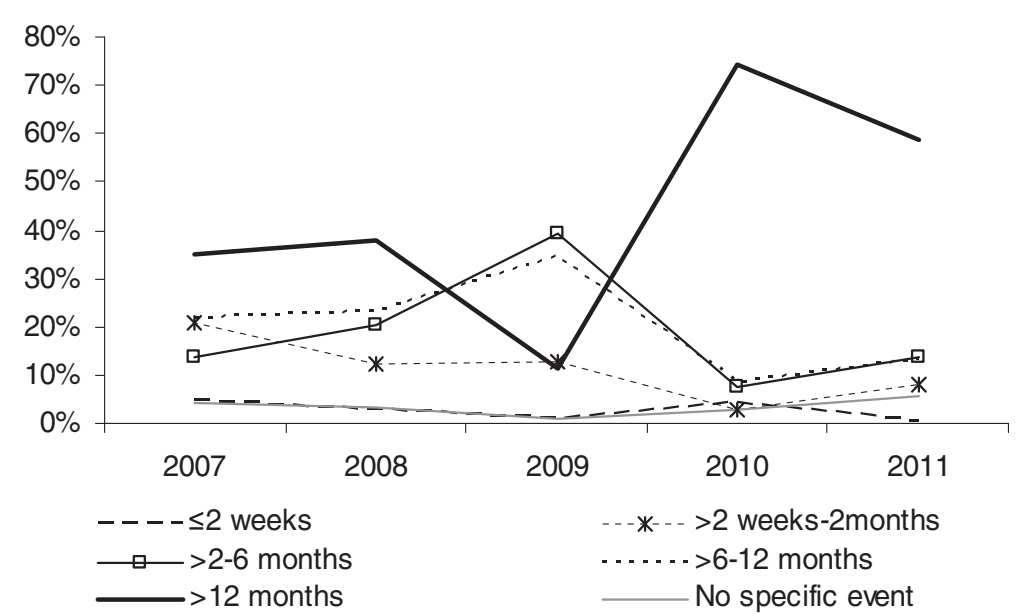

Figure 1 Time from triggering event to therapy by year for new patients in the MSF mental health treatment program in Gaza Strip, January 2007-July 2011.

anxiety disorders rose again to levels similar to before OCL.

Among patients older than 15, the most common diagnoses were PTSD, depression, other anxiety disorders, and ASD. Primary diagnoses of PTSD and ASD were more common in men OR $=1.98(1.38-2.84)$ while depression and other anxiety disorders were more common in women $\mathrm{OR}=1.91(1.34-2.72)$. In the first half of 2009, diagnoses of ASD and PTSD increased compared to the previous year, $\mathrm{OR}=2.70(1.40-5.19)$. Compared to this period, in the second half of 2009 these two diagnoses proportionally decreased while depression and other anxiety disorders became more common, $\mathrm{OR}=4.97$ (2.29-10.80). Patient diagnoses by age-group and year are shown in Tables 4 and 5.

One fifth of patients (284/1357) had more than one diagnosed psychopathology. PTSD as primary or secondary diagnosis $(n=157)$ most commonly coexisted with depression $(84 / 157,54 \%)$ or other anxiety disorder (23/ 157, 15\%); the next most common were depression $(n=146)$ with other anxiety disorders $(29 / 146,20 \%)$.

Baseline severity was recorded for 1286 of 1357 patients (Table 6). Patients older than 15 years were more likely to be considered severe at baseline, $\mathrm{OR}=2.40$ (1.89-3.03), while moderate baseline severity was more common after OCL, OR =2.06 (1.60-2.66). In a multivariate model $(n=1263)$ including age, traumatic events, time to care, referral source, treatment location, and time period, variables associated with high baseline severity were: age $>15$ years, $\mathrm{OR}=1.61(1.23-2.10)$; greater number of traumatic events, $\mathrm{OR}=1.33(1.22-1.45)$; shorter time interval between the triggering event and seeking care $\mathrm{OR}=$ 0.79 (0.72-0.87); and being referred by a MSF or other health staff, $\mathrm{OR}=2.22(1.69-2.91)$; having home sessions was borderline significant, $\mathrm{OR}=1.32$ (1.00-1.74); and pre/post OCL period (2007-2008 vs. 2009-2011) were not predictors of high baseline severity, $\mathrm{OR}=0.83$ (0.62-1.12).

The median number of sessions for the period 2007-2011 was 9 (IQR=6-12), peaking in 2009 for patients older than 15 years and 2010 for those 15 years and younger. A multivariate model $(n=1251)$ showed that adults, $B=1.05, \mathrm{p}<0.001$; higher baseline severity, $\beta=0.73, \mathrm{p}<0.001$; and the post $\mathrm{OCL}$ years (2009-2011), $\beta=1.19, \mathrm{p}<0.001$ were all positively associated with greater number of sessions. Most patients (821/1332, 61\%) received individual therapy, though children and younger adolescents were more likely than older adolescents and adults to receive family or dyad therapy $\left(\chi^{2}=269.2, \mathrm{p}<0.001\right)$. No significant association between number of sessions or therapy type and time period was noted.

Most patients either improved $(n=1059,78 \%)$ or had resolved the issue for which treatment was sought $(\mathrm{n}=63,5 \%) ; 141$ (10\%) remained unchanged and $2(1 \%)$ had worsened; therapeutic outcome information was not available for 92 (7\%). Greatest proportion of improvements were noted in 2009-2010 (87-88\% compared to $74-77 \%$ in other years), but in multivariate models including age, baseline severity and time period, no statistically significant associations were found with improvement or recovery and time period. Of the 14 patients diagnosed with ASD in 2009, 13 (93\%) showed improvement or complete resolution. Of 169 with PTSD as the principal diagnosis the same year, 221 (91\%) showed improvement or resolution; 11 (5\%) showed no change and 10 (4\%) were not evaluable. As a whole, those with anxiety disorders (ASD, PTSD, separation anxiety or other anxiety disorders) as principal diagnosis showed improvement $(855 / 1005,85 \%)$ more often 
Table 3 Baseline clinical expression and main complaints of MSF program patients by age category, 2007-2011

\begin{tabular}{|c|c|c|c|c|}
\hline & \multicolumn{4}{|c|}{ Age category } \\
\hline & \multicolumn{2}{|c|}{$<15$ years } & \multicolumn{2}{|c|}{$\geq 15$ years } \\
\hline & $\bar{N}$ & $\%$ & $\bar{N}$ & $\%$ \\
\hline \multicolumn{5}{|l|}{ Clinical expression } \\
\hline Distress/anxiety & 285 & (34) & 161 & $(32)$ \\
\hline Inhibition/withdrawal & 204 & (24) & 46 & (9) \\
\hline Sadness/crying & 163 & (19) & 204 & $(41)$ \\
\hline Unspecified & 147 & (17) & 47 & (9) \\
\hline Aggression/anger & 29 & (3) & 23 & (5) \\
\hline Agitation/logorrhea & 13 & $(2)$ & 20 & (4) \\
\hline Total & 841 & $(100)$ & 501 & $(100)$ \\
\hline \multicolumn{5}{|l|}{ Patient Complaints } \\
\hline Fear & 568 & (67) & 93 & (18) \\
\hline Sleep disturbance & 218 & (26) & 172 & (34) \\
\hline Enuresis & 328 & (39) & 8 & (2) \\
\hline Sadness & 56 & (7) & 163 & $(32)$ \\
\hline Aggressivity & 118 & (14) & 65 & (13) \\
\hline Intrusive memories & 57 & (7) & 105 & $(21)$ \\
\hline Anxiety/worries & 56 & (7) & 100 & $(20)$ \\
\hline Somatic complaints & 21 & $(2)$ & 90 & $(18)$ \\
\hline Grief & 18 & $(2)$ & 65 & (13) \\
\hline Avoidance & 35 & (4) & 20 & (4) \\
\hline Pain & 8 & (1) & 38 & (8) \\
\hline Hyperactivity & 43 & (5) & 2 & (0) \\
\hline Concentration problem & 23 & (3) & 14 & (3) \\
\hline Other complaint & 20 & $(2)$ & 15 & (3) \\
\hline Speech problem & 29 & (3) & 2 & (0) \\
\hline Learning disability & 22 & (3) & 2 & (0) \\
\hline Weakness & 5 & (1) & 11 & (2) \\
\hline Suicidal/risky behavior & 4 & $(0)$ & 8 & (2) \\
\hline Eating problems & 7 & $(1)$ & 4 & (1) \\
\hline Delusions/hallucinations & 1 & (0) & 2 & (0) \\
\hline Total complaints & 1637 & (193) & 979 & (193) \\
\hline Total patients & 846 & $(100)$ & 506 & (100) \\
\hline
\end{tabular}

Clinical expression not recorded for 15 patients.

Patient complaints not recorded for 5 patients.

than those with depression as principal diagnosis $(141 / 183,77 \%)$ (Fisher's exact, $\mathrm{p}<0.01$ ).

The majority of patients $(\mathrm{n}=1008,74 \%)$ ended sessions by mutual agreement with the therapist; 52 (4\%) were externally referred, mostly to local institutions, psychologists or psychiatrists for specialized care; 194 (14\%) defaulted or were missing end of therapy information in the database. Symptoms persisted for 20\% (266/1357) of patients, most notably: fear, anxiety or worrying $(n=64)$, sadness $(n=34)$, and enuresis $(n=46)$.

\section{Discussion}

This descriptive analysis of patient information at the MSF mental health program in Gaza Strip is based on records from two years prior through two and a half years after the bombardment of Gaza Strip between December 2008 and January 2009. The analysis detected proximal and distal socio-economic, symptomatic and diagnostic characteristics potentially associated with exposure to the violence of OCL.

Some background temporal changes were noted, such as a change in referral patterns, as well as the age, sex and socio-economic condition of patients. From 2007 to 2011 community, family and auto referrals became more common in contrast to institutional and health practitioner referrals; this is not unexpected as the organization becomes better known in the community and recommendations from former patients increase. That more vulnerable segments of the population (women, younger patients, and those with greater socioeconomic needs) were seen in later years reflects a natural evolution of the program and the nature of informal referral networks in contrast to institutional and professional referrals. Some changes in baseline severity, diagnostic trends and number of sessions may also be associated with this socio-demographic shift.

Against the backdrop of programmatic and other temporally related changes, we noted some likely associations with the bombardment during Operation Cast Lead (OCL). We found a significant increase in new patients with low to middle to socio-economic needs immediately after the war. This constituted a temporary reversal of the longer-term pattern and suggests that exposure to severe violence or the destruction of material goods and traditional support networks could have an equalizing effect in terms of need for psychological support or tendency to seek it.

Due to increased demand and capacity after OCL, the average number of new monthly patients at the MSF program doubled for the following two and a half years. Noted changes among new patients after OCL were a prompt increases in diagnosis of acute stress disorder (ASD), followed by posttraumatic stress disorder (PTSD) in the first 6 months, and depression and other anxiety disorders thereafter (the former mostly for the older age group and the latter for younger); multiple diagnoses were also common. While trauma related stress often subsides weeks after the precipitating event, $[27,28]$ diagnosed ASD is a recognized predictor of psychiatric sequelae [29]. PTSD, depression and other mental disorders are common in contexts of conflict and displacement, linked to cumulative lifetime traumatic events, modulated by adversity and daily life stressors $[1,3,4,6,30]$. 
Table 4 Main diagnosis for patients 15 years of age and younger by year of entry to MSF program

\begin{tabular}{|c|c|c|c|c|c|c|c|c|c|c|c|c|}
\hline \multirow{2}{*}{$\begin{array}{l}\text { Year } \\
\text { Main diagnosis }\end{array}$} & \multicolumn{2}{|l|}{2007} & \multicolumn{2}{|c|}{2008} & \multicolumn{2}{|c|}{2009} & \multicolumn{2}{|c|}{2010} & \multicolumn{2}{|c|}{2011} & \multicolumn{2}{|c|}{ Total } \\
\hline & No. & $(\%)$ & No. & $(\%)$ & No. & $(\%)$ & No. & $(\%)$ & No. & $(\%)$ & No. & $(\%)$ \\
\hline Acute stress disorder & 1 & (2) & 2 & $(2)$ & 6 & (2) & 6 & $(2)$ & 3 & $(2)$ & 18 & $(2)$ \\
\hline PTSD & 21 & (37) & 60 & (54) & 169 & (62) & 123 & $(48)$ & 87 & (59) & 460 & $(54)$ \\
\hline Other anxiety disorder & 12 & $(21)$ & 24 & $(21)$ & 36 & (13) & 90 & (35) & 50 & (34) & 212 & $(25)$ \\
\hline Depression & 1 & (2) & 2 & $(2)$ & 14 & (5) & 9 & (4) & 2 & $(1)$ & 28 & (3) \\
\hline Brief psychotic disorder & 0 & $(0)$ & 0 & (0) & 2 & (1) & 0 & (0) & 0 & (0) & 2 & (0) \\
\hline Other psychotic disorder & 1 & $(2)$ & 0 & $(0)$ & 0 & (0) & 0 & $(0)$ & 0 & $(0)$ & 1 & $(0)$ \\
\hline Adjustment disorder & 2 & (4) & 5 & (4) & 4 & (1) & 3 & $(1)$ & 0 & (0) & 14 & $(2)$ \\
\hline Learning disability & 0 & $(0)$ & 1 & $(1)$ & 1 & (0) & 0 & (0) & 0 & (0) & 2 & (0) \\
\hline Communication disorder & 0 & $(0)$ & 1 & $(1)$ & 9 & (3) & 3 & $(1)$ & 0 & (0) & 13 & $(2)$ \\
\hline Attention Deficit Hyperactivity & 0 & (0) & 0 & (0) & 7 & (3) & 1 & (0) & 2 & $(1)$ & 10 & (1) \\
\hline Eating disorder & 0 & $(0)$ & 1 & (1) & 1 & (0) & 0 & (0) & 0 & (0) & 2 & (0) \\
\hline Parent-child relationship & 1 & $(2)$ & 0 & (0) & 4 & (1) & 4 & $(2)$ & 0 & (0) & 9 & (1) \\
\hline Separation Anxiety & 0 & $(0)$ & 0 & $(0)$ & 8 & (3) & 7 & (3) & 0 & (0) & 15 & $(2)$ \\
\hline Other diagnosis & 2 & (4) & 3 & (3) & 1 & (0) & 0 & (0) & 0 & (0) & 6 & $(1)$ \\
\hline No main diagnosis & 0 & (0) & 0 & (0) & 2 & (1) & 0 & (0) & 0 & (0) & 2 & (0) \\
\hline Somatic disorder & 1 & $(2)$ & 1 & (1) & 1 & (0) & 0 & (0) & 0 & (0) & 3 & $(0)$ \\
\hline Personality disorder & 0 & $(0)$ & 0 & $(0)$ & 0 & (0) & 1 & (0) & 0 & (0) & 1 & (0) \\
\hline Distress /no disorder & 7 & $(12)$ & 7 & (6) & 6 & (2) & 6 & $(2)$ & 3 & $(2)$ & 29 & (3) \\
\hline Missing value & 8 & (14) & 5 & (4) & 3 & (1) & 2 & $(1)$ & 1 & (1) & 19 & $(2)$ \\
\hline Total & 57 & $(100)$ & 112 & $(100)$ & 274 & $(100)$ & 255 & $(100)$ & 148 & $(100)$ & 846 & $(100)$ \\
\hline
\end{tabular}

In this impoverished and protracted, violent context, patients 15 years and younger had threefold the number of traumatic events per year of life compared to older patients, suggesting a more volatile environment in recent years. Yet despite continued adversity, one and two years after OCL a large proportion of new patients still identified a triggering event one or more years prior; the time frame suggesting that observed patterns were OCL related, or in some cases preceding it. While OCL may have constituted the principal traumatic event for many including late presenters, it may also have been the most poignant among a lifetime of accumulated daily stressors and traumatic events. It is also possible that the late presenting cases were at least partially due the continued stress exhausting resilience and coping mechanisms. The population of Gaza has been exposed to conflict over many years, which should have contributed to improved coping mechanisms [31]. Yet, it is evident that OCL impaired social networks and community capacities. It is possible that for many, built up resilience and coping mechanisms were not sufficient to manage stress and psychological needs [32].

Between 2009 and 2011 MSF received fewer professionally referred adults with more proximal triggering event, which together were found to be associated with high baseline severity. Perhaps consequently, new patients after the war tended to have moderate rather severe baseline condition. Additionally, barring changes in application of rating criteria by new personnel and increasing direct referrals of high severity cases elsewhere, it is possible that the war resulted in an increase in common disorders with moderate severity, or at least the likelihood of seeking support for them. PTSD and depression were also associated with substantial disability in other post-conflict settings [33,34].

While additional rigorous assessments are needed, psychotherapeutic and psychosocial interventions show a beneficial effect of addressing trauma related disorders in humanitarian settings. Of 13 randomized clinical controlled trials included in a recent meta-analysis, psychotherapy and psychosocial support showed beneficial effects on PTSD in adults, while group psychotherapy, psychosocial and school based support showed, more generally, benefits on children with internalizing disorders [4]. In Gaza, several interventions involving psychodynamic or cognitive therapeutic frameworks have shown promising results in reducing distress and enhancing coping strategies and resilience among war-affected children. More specifically, school based interventions including mediation, counseling, and psychodrama sessions provided emotional relief to the children or showed decreases in behavioral problems [9]. In our 
Table 5 Main diagnosis for patients 16 years of age and older by year of entry to MSF program

\begin{tabular}{|c|c|c|c|c|c|c|c|c|c|c|c|c|}
\hline \multirow{2}{*}{$\begin{array}{l}\text { Year } \\
\text { Main diagnosis }\end{array}$} & \multicolumn{2}{|l|}{2007} & \multicolumn{2}{|c|}{2008} & \multicolumn{2}{|c|}{2009} & \multicolumn{2}{|c|}{2010} & \multicolumn{2}{|l|}{2011} & \multicolumn{2}{|c|}{ Total } \\
\hline & No. & $(\%)$ & No. & $(\%)$ & No. & $(\%)$ & No. & (\%) & No. & (\%) & No. & (\%) \\
\hline Acute stress disorder & 8 & (9) & 4 & (4) & 8 & (6) & 3 & $(2)$ & 0 & (0) & 23 & (5) \\
\hline PTSD & 35 & (39) & 46 & $(49)$ & 72 & (53) & 31 & $(23)$ & 15 & $(27)$ & 199 & (39) \\
\hline Other anxiety disorder & 6 & (7) & 8 & (9) & 13 & (10) & 33 & $(25)$ & 15 & (27) & 75 & $(15)$ \\
\hline Depression & 24 & $(27)$ & 22 & (23) & 35 & (26) & 52 & (39) & 21 & (38) & 154 & $(30)$ \\
\hline Brief psychotic disorder & 0 & $(0)$ & 0 & (0) & 0 & (0) & 0 & (0) & 0 & $(0)$ & 0 & $(0)$ \\
\hline Other psychotic disorder & 0 & $(0)$ & 0 & $(0)$ & 0 & (0) & 0 & (0) & 0 & (0) & 0 & $(0)$ \\
\hline Adjustment disorder & 2 & $(2)$ & 4 & $(4)$ & 1 & $(1)$ & 0 & (0) & 1 & $(2)$ & 8 & $(2)$ \\
\hline Learning disability & 0 & $(0)$ & 0 & $(0)$ & 0 & $(0)$ & 0 & (0) & 0 & $(0)$ & 0 & $(0)$ \\
\hline Communication disorder & 0 & (0) & 0 & $(0)$ & 0 & (0) & 1 & $(1)$ & 0 & $(0)$ & 1 & $(0)$ \\
\hline Attention Deficit Hyperactivity & 0 & $(0)$ & 0 & $(0)$ & 0 & $(0)$ & 0 & (0) & 0 & (0) & 0 & $(0)$ \\
\hline Eating disorder & 1 & $(1)$ & 0 & (0) & 0 & (0) & 0 & $(0)$ & 0 & $(0)$ & 1 & $(0)$ \\
\hline Parent-child relationship & 0 & $(0)$ & 0 & (0) & 0 & (0) & 0 & $(0)$ & 0 & $(0)$ & 0 & $(0)$ \\
\hline Separation Anxiety & 1 & (1) & 0 & $(0)$ & 0 & (0) & 0 & (0) & 0 & (0) & 1 & $(0)$ \\
\hline Other diagnosis & 0 & $(0)$ & 1 & (1) & 0 & $(0)$ & 3 & (2) & 0 & (0) & 4 & $(1)$ \\
\hline No main diagnosis & 0 & (0) & 0 & (0) & 0 & (0) & 0 & (0) & 0 & (0) & 0 & (0) \\
\hline Somatic disorder & 1 & (1) & 0 & $(0)$ & 1 & (1) & 1 & (1) & 0 & (0) & 3 & (1) \\
\hline Personality disorder & 0 & $(0)$ & 0 & $(0)$ & 1 & (1) & 2 & $(2)$ & 0 & (0) & 3 & (1) \\
\hline Distress /no disorder & 3 & (3) & 6 & (6) & 2 & (1) & 6 & (5) & 2 & (4) & 19 & (4) \\
\hline Missing value & 8 & (9) & 3 & (3) & 2 & (1) & 1 & $(1)$ & 1 & $(2)$ & 15 & (3) \\
\hline Total & 89 & $(100)$ & 94 & $(100)$ & 135 & $(100)$ & 133 & $(100)$ & 55 & $(100)$ & 506 & (100) \\
\hline
\end{tabular}

Principal diagnosis not recorded for 15 patients.

own intervention in Gaza, West Bank and other conflict settings, programmatic data review showed an overall benefit of psychotherapy and other mental health support [21-24]. Here, we present evidence of beneficial effects of psychotherapy on the vast majority of patients. We also describe a timeline and age related differences which if reproduced in other settings could be informative to personnel and agencies preparing to assist communities following intense violence in longer-term conflicts.
Several limitations apply to this study. These findings were based on routinely collected data, are not hypothesis driven and lack a control group; furthermore, some significant findings may simply be due to the large number of comparisons made. Second, despite efforts to standardize assessments, there is frequent turnover of expatriate staff in the program with implications on the consistency with which severity, diagnosis and treatment outcomes are assigned. Third, this is clinic based thus not necessarily representative of characteristics and

Table 6 Baseline severity level by age group and year of entry to MSF program

\begin{tabular}{|c|c|c|c|c|c|c|c|c|c|c|c|c|}
\hline & \multicolumn{2}{|c|}{2007} & \multicolumn{2}{|c|}{2008} & \multicolumn{2}{|c|}{2009} & \multicolumn{2}{|c|}{2010} & \multicolumn{2}{|c|}{2011} & \multicolumn{2}{|c|}{ Total } \\
\hline & No. & (\%) & No. & $(\%)$ & No. & $(\%)$ & No. & (\%) & No. & (\%) & No. & (\%) \\
\hline \multicolumn{13}{|c|}{ Patients 15 years of age and younger } \\
\hline mild & 1 & $(2)$ & 20 & $(20)$ & 6 & (2) & 3 & $(1)$ & 9 & (6) & 39 & (5) \\
\hline moderate & 38 & $(69)$ & 43 & $(43)$ & 173 & (63) & 171 & $(71)$ & 109 & (78) & 534 & $(66)$ \\
\hline severe & 16 & $(29)$ & 38 & (38) & 94 & (34) & 67 & $(28)$ & 22 & (16) & 237 & $(29)$ \\
\hline Total & 55 & $(100)$ & 101 & $(100)$ & 273 & $(100)$ & 241 & $(100)$ & 140 & (100) & 810 & $(100)$ \\
\hline \multicolumn{13}{|c|}{ Patients 16 years of age and older } \\
\hline mild & 7 & (9) & 10 & (11) & 1 & (1) & 0 & (0) & 1 & (2) & 19 & (4) \\
\hline moderate & 38 & (48) & 29 & (33) & 57 & (43) & 69 & (55) & 25 & (54) & 218 & (46) \\
\hline severe & 35 & (44) & 49 & (56) & 75 & (56) & 56 & $(45)$ & 20 & (43) & 235 & $(50)$ \\
\hline Total & 80 & $(100)$ & 88 & (100) & 133 & $(100)$ & 125 & $(100)$ & 46 & (100) & 472 & (100) \\
\hline
\end{tabular}


changes at community level. Fourth, it was not possible to evaluate patient evolution from data collected, other than therapeutic outcome and adherence. Rather, analysis of temporal trends, including effects of the war on severity, symptomatology and diagnosis, are based on differences across new patients at different periods. Another potential limiting factor is that new versus repeat patient status was not recorded at individual level, although these were estimated to represent less than $5 \%$ of the total patient population. It is possible that returning patients may have different profiles than new patients. Similarly, since research was not the focus of the clinical intervention, some information available to clinicians was not systematically recorded in the patient follow-up database. In this instance symptom severity, traumatizing event timing and changes in operational capacity information would have enhanced the analysis of data and interpretability of results. Recording these in the future would be of benefit. Lastly, many unmeasured factors exist which could be confounding findings, such as specifics of referrals sources and reasons for them, community-wide socio-economic changes, alternative treatment facilities, and temporal trends due to program related changes.

While not a limitation, the high threshold and fluctuating levels of violence and trauma associated with the long standing conflict also makes it difficult to discern changes specific to one particular bombardment, albeit intense and long-lasting.

These findings are part of an operational review; they are meant to be hypothesis generating and would need to be confirmed in a properly designed longitudinal study. Thus from our findings we hypothesize that sudden mass exposure to acute violence in a protracted conflict may elicit a sustained increase in demand of mental health services. Such events may have an equalizing effect in terms of need for psychological support, which may be reflected in a broadening of socio-economic profile of care seekers. Coping mechanisms and resilience eroded by mass destruction may result in late presenters who still refer to a distant triggering event. Future studies would also benefit from independent assessment of resilience, severity and impact of care utilizing locally validated quantitative instruments.

\section{Conclusion}

These findings suggest that mental health related humanitarian relief in protracted conflict might need to prepare for an increase in patients with changing profile over an extended period following an acute flare-up in violence. Specifically, observed trends suggest presentation of socio-economically diverse group of patients with a range of disorders starting with acute stress followed by PTSD and eventually depression and other anxiety disorders. The effects of a serious increase in violence at community wide levels do not seem to extinguish rapidly, as suggested by continued high demand for services and increasing time to treatment with long recall to triggering events.

\section{Abbreviations}

ASD: Acute stress disorder; 3 : Regression coefficient for linear regression; IQR: Inter-quartile range $\left(25^{\text {th }}-75^{\text {th }}\right.$ percentile); OCL: Operation Cast Lead; OR: Odds ratio; PTSD: Posttraumatic stress disorder; $x^{2}$ : Chi square test.

\section{Competing interests}

The authors declare that they have no competing interests.

\section{Authors' contributions}

AEL had full access to the data of the study and takes full responsibility for the accuracy of the data analysis. AEL, GC, RFG, MRM participated in the interpretation of the results and critical revision of the manuscript. HT, AM participated in the collection and quality control of the data. All authors read and approved the final manuscript.

\section{Acknowledgements}

We gratefully acknowledge the support provided by all MSF field coordination and headquarters teams who contributed to the collection of information and program activities. In particular we are grateful to the project psychologists, as well as Dr. Frederique Drogoul (psychiatric referent at MSF-France).

\section{Author details}

'Epicentre, 8 rue Saint Sabin, Paris 75011, France. ${ }^{2}$ School of Medicine, Los Andes University, Carrera 7 N 116-05, Bogotá, Colombia. ${ }^{3}$ Médecins Sans Frontières, 8 rue Saint Sabin, Paris 75011, France. ${ }^{4}$ Medecins Sans Frontieres, El Hajaj Ibn Youssuf Street, Shufat Main road, Jerusalem. ${ }^{5}$ Cochin Hospital, Université Paris Descartes, Unité INSERM 669, Paris 75014, France.

Received: 25 July 2012 Accepted: 18 October 2012

Published: 23 October 2012

\section{References}

1. Miller KE, Rasmussen A: War exposure, daily stressors, and mental health in conflict and post-conflict settings: bridging the divide between trauma-focused and psychosocial frameworks. Soc Sci Med 2010, 70:7-16.

2. Reed RV, Fazel M, Jones L, Panter-Brick C, Stein A: Mental health of displaced and refugee children resettled in low-income and middleincome countries: risk and protective factors. Lancet 2012, 379:250-265.

3. Steel Z, Chey T, Silove D, Marnane C, Bryant RA, van Ommeren M: Association of torture and other potentially traumatic events with mental health outcomes among populations exposed to mass conflict and displacement: a systematic review and metaanalysis. JAMA 2009, 302:537-549.

4. Tol WA, Barbui C, Galappatti A, Silove D, Betancourt TS, Souza R, et al: Mental health and psychosocial support in humanitarian settings: linking practice and research. Lancet 2011, 378:1581-1591.

5. Canetti D, Galea S, Hall BJ, Johnson RJ, Palmieri PA, Hobfoll SE: Exposure to prolonged socio-political conflict and the risk of PTSD and depression among Palestinians. Psychiatry 2010, 73:219-231.

6. De Jong JT, Komproe IH, Van Ommeren M, El Masri M, Araya M, Khaled N, et al: Lifetime events and posttraumatic stress disorder in 4 postconflict settings. JAMA 2001, 286:555-562.

7. Khamis V: Impact of war, religiosity and ideology on PTSD and psychiatric disorders in adolescents from Gaza Strip and South Lebanon. Soc Sci Med 2012, 74:2005-2011.

8. Madianos MG, Sarhan AL, Koukia E: Major depression across West Bank: a crosssectional general population study. Int I Soc Psychiatry 2011, 58(3):315-322 
9. Thabet AA, Vostanis P: Impact of political violence and trauma in Gaza on children's mental health and types of interventions: a review of research evidence in a historical context. Int J Peace Dev Stud 2012, 2:214-218.

10. UNWRA: West Bank \& Gaza Strip population census of 2007: UNWRA; 2010 Ref Type: Report. Electronic Report available at http://www.ochaopt.org/ documents/opt_nonsector_unrwa_population_census2007_jan_2010.pdf. Accessed 06 June 2012.

11. Horton R: The occupied Palestinian territory: peace, justice, and health. Lancet 2009, 373:784-788.

12. Batniji R, Rabaia Y, Nguyen-Gillham V, Giacaman R, Sarraj E, Punamaki RL, et al: Health as human security in the occupied Palestinian territory6. Lancet 2009, 373:1133-1143.

13. Abu-Rmeileh NME, Hammoudeh W, Giacaman R: Humanitarian crisis and social suffering in Gaza Strip: an initial analysis of aftermath of latest Israeli war. Lancet 2010, Ref Type: Abstract. http://download.thelancet.com/ flatcontentassets/pdfs/palestine/S014067361060846X.pdf. Accessed 06 June 2012.

14. Dershowitz A: The Case Against the Goldstone Report: A Study in Evidentiary Bias. Digital Access to Scholarship at Harvard 2012, 16:5. 2012. Ref Type: Electronic Citation.

15. United Nations Human Rights Council: Human Rights In Palestine And Other Occupied Arab Territories: Report of the United Nations Fact-Finding Mission on the Gaza Conflict. A/HRC/12/48:: United Nations; 2009. Report: Ref Type.

16. Ghosh N, Mohit A, Murthy RS: Mental health promotion in post-conflict countries. J R Soc Promot Health 2004, 124:268-270.

17. Rousseau C, Measham T, Moro MR: Working with interpreters in child mental health. Child Adolesc Ment Health 2012, 16:55-59.

18. Baubet T, Moro MR: Cultures et soins du trauma psychique en situation humanitaire. In Soigner malgré tout. "Trauma, cultures et soins". Edited by Baubet T, Le Roch K, Bitar D, Moro MR. Grenoble: La Pensée Sauvage; 2003:69-93.

19. Garland C: Understanding trauma: a psycho-analytical approach. London: Duckworth; 1998.

20. Weissman MM, Markowitz JC, Klerman GL: Comprehensive Guide To Interpersonal Psychotherapy. New York: Basic Books and Perseus Books Group; 2000.

21. Espie E, Gaboulaud V, Baubet T, Casas G, Mouchenik Y, Yun O, et al: Trauma-related psychological disorders among Palestinian children and adults in Gaza and West Bank, 2005-2008. Int J Ment Health Syst 2009, $3: 21$.

22. Hustache S, Moro MR, Roptin J, Souza R, Gansou GM, Mbemba A, et al: Evaluation of psychological support for victims of sexual violence in a conflict setting: results from Brazzaville, Congo5. Int J Ment Health Syst 2009, 3:7.

23. Sanchez-Padilla E, Casas G, Grais RF, Hustache S, Moro MR: The Colombian conflict: a description of a mental health program in the Department of Tolima4. Confl Health 2009, 3:13.

24. Gaboulaud V, Reynaud C, Moro MR, Roptin J, Lachal C, Brown V, et al: Psychological support for Palestinian children and adults: an analysis of data from people referred to the Medecins Sans Frontieres programme for behavioural and emotional disorders in the occupied Palestinian territory. Intervention 2010, 8:131-142.

25. American Psychiatric Association: Diagnostics and statistical manual of mental disorders. 4th edition. Washington D.C: American Psychiatric Association; 2000

26. Sturm G, Baubet T, Moro MR: Culture, trauma and subjectivity: the french ethnopsychoanalytic approach. Traumatolgoy 2010, 16:27-38.

27. Silove D, Steel Z: Understanding community psychosocial needs after disasters: implications for mental health services. J Postgrad Med 2006 52:121-125.

28. Bryant RA: Early predictors of posttraumatic stress disorder. Biol Psychiatry 2003, 53:789-795.

29. Bryant RA, Creamer M, O'Donnell M, Silove D, McFarlane AC: The capacity of acute stress disorder to predict posttraumatic psychiatric disorders. $J$ Psychiatr Res 2012, 46:168-173.

30. Porter M, Haslam N: Predisplacement and postdisplacement factors associated with mental health of refugees and internally displaced persons: a meta-analysis. JAMA 2005, 294:602-612.

31. Bonanno GA, Westphal M, Mancini AD: Resilience to loss and potential trauma6. Annu Rev Clin Psychol 2011, 7:511-535.
32. Hobfoll SE, Mancini AD, Hall BJ, Canetti D, Bonanno GA: The limits of resilience: distress following chronic political violence among Palestinians1. Soc Sci Med 2011, 72:1400-1408.

33. Silove D, Bateman CR, Brooks RT, Fonseca CA, Steel Z, Rodger J, et al: Estimating clinically relevant mental disorders in a rural and an urban setting in postconflict Timor Leste. Arch Gen Psychiatry 2008, 65:1205-1212

34. Thapa SB, Hauff E: Perceived needs, self-reported health and disability among displaced persons during an armed conflict in Nepal1. Soc Psychiatry Psychiatr Epidemiol 2012, 47:589-595.

doi:10.1186/1752-1505-6-8

Cite this article as: Llosa et al:: Short and longer-term psychological consequences of Operation Cast Lead: documentation from a mental health program in the Gaza Strip. Conflict and Health 2012 6:8.

\section{Submit your next manuscript to BioMed Central and take full advantage of:}

- Convenient online submission

- Thorough peer review

- No space constraints or color figure charges

- Immediate publication on acceptance

- Inclusion in PubMed, CAS, Scopus and Google Scholar

- Research which is freely available for redistribution 